http://jmscr.igmpublication.org/home/ ISSN (e)-2347-176x ISSN (p) 2455-0450

crossref DOI: https://dx.doi.org/10.18535/jmscr/v7i11.89

Journal Of Medical Science And Clinical Research

\title{
A study of anthropometric measurements and different vascular complications in obese type 2 diabetes mellitus patients from central India
}

Authors

\section{Dr Archana Verma ${ }^{1}$, Dr Dharshan Gowda ${ }^{2 *}$, Dr Dharmendra Jhavar ${ }^{3}$, Dr Umesh Kumar Chandra ${ }^{4}$, Dr Bharat Kumar Parmar}

${ }^{1}$ DNB Neurology, Associate Professor, Department of Medicine, MGM Medical College, Indore, MP, India

${ }^{2}$ Junior Resident, Department of Medicine, MGM Medical College, Indore, MP, India

${ }^{3}$ MD Medicine, Professor, Department of Medicine, MGM Medical College, Indore, MP, India

${ }^{4}$ MD Medicine, Senior Resident, Department of Medicine, MGM Medical College, Indore, MP, India

${ }^{5}$ MD Medicine, Ex Resident, Department of Medicine, MGM Medical College, Indore, MP, India

*Corresponding Author

Dr Dharshan Gowda

Junior Resident, Department of Medicine, MGM Medical College, Indore, MP, India

\begin{abstract}
Introduction: India is experiencing an epidemic of Type-2 Diabetes mellitus and related disorders. With an estimated 50.8 million diabetic people, India has the world's largest diabetes population. Individual with Type 2 DM are at particular risk of the adverse consequences of obesity. The interaction of both disorders with other components of the metabolic syndrome culminates in an increase in macro-vascular and micro-vascular complications and associated reduction in quality of life.

Materials and Methods: Present work was conducted in department of medicine, MGM Medical College, Indore, from October 2012 to September 2013. 100 cases with type 2 diabetes mellitus having associated obesity were taken for present work.

Results: Out of 70 female cases, $61 \%$ female cases had BMI between 25-29.9\%. Only 5\% female cases had BMI >or=40. Out of 30 male cases, 70\% of male cases had BMI Between 25-29.9. In our study none of male case had BMI >or=40. In female patients, $11 \%, 22 \%$, and $67 \%$ patients had Waist Hip Ratio (WHR) $<0.81,0.81-85$, and $>0.85 \%$ respectively. $46 \%$ of male cases had $<$ or $=0.95$ WHR. $30 \%$ male cases had $>1.0$ WHR.

Conclusions: Basic anthropometrics measurements $(B M I+W H R)$ are simple clinical parameters to evaluate obese DM type 2 cases for CVS complications. Obese DM type 2 cases with abnormal WHR and BMI may have abnormalities in ECG \& 2D ECHO DOPPLER. Hence ECG \& 2D ECHO DOPPLER study may help for proper evaluation of obese DM type 2 cases.

Keywords: BMI, Diabetes Mellitus, Obesity, Waist hip ratio.
\end{abstract}

\section{Introduction}

India is experiencing an epidemic of Type-2 Diabetes mellitus and related disorders. With an estimated 50.8 million diabetic people, India has the world's largest diabetes population. Individual with Type $2 \mathrm{DM}$ are at particular risk of the adverse consequences of obesity. The interaction of both disorders with other components of the 
metabolic syndrome culminates in an increase in macro-vascular and micro-vascular complications and associated reduction in quality of life.

The American heart association has designed DM as $\mathrm{CAD}$ risk equivalent. Type 2 diabetes mellitus patients without a prior MI have a similar risk for coronary artery related events as non-diabetic individuals who had a prior MI.

Obesity is increasing health problem worldwide including the developing countries. In India, obesity is emerging as an important health problem particularly in urban area. Almost 30$65 \%$ of adults urban Indians are either overweight or obese or have abdominal obesity. The rising prevalence overweight and obesity in India has a direct correlation with the increasing prevalence of obesity related co-morbidities; systemic hypertension, metabolic syndrome, dyslipidaemia, type2 diabetes mellitus and cardio vascular disease (CVD).

In our study, we studied various anthropometric parameters in diabetic patients and correlated with clinical outcome of those studied patients.

\section{Materials and Methods}

Present work was conducted in department of medicine Indore from October 2012 to September 2013. 100 cases with type 2 diabetes mellitus having associated obesity were taken for present work. Patients were taken randomly from various medical wards and OPDs.

\section{Inclusion Criteria}

1. Age 25 years to 60 years

2. Both male and female cases.

3. Cases who met the criteria for Diabetes mellitus type 2 .

4. Cases with BMI $>25$.

5. Old as well as newly detected diabetic cases with various risk factors.

\section{Exclusion Criteria}

1. Age $<25$ year and case with age $>60$ years not included because cases with $<25$ year of age may have often diabetes mellitus type 1 and severe other age related diseases may see in senior citizens.
2. Cases with the normal and subnormal BMI.

3. Seriously ill cases with multisystem disease.

4. Cases were excluded who had clinical hypo or hyperthyroidism.

5. COPD cases.

6. Cases with deranged renal function.

The anthropometric measurements of cases were recorded by observer and his colleagues, using standard protocol. Cases were instructed to empty their bladder prior to anthropomorphic measurements.

Height was measured to the nearest $0.1 \mathrm{~cm}$ using by inches centimeter tape pasted to wall. Cases were asked to stand erect while their occiput shoulder hips and heel touched the wall. A firm cardboard was put over the vertex to get the height in centimeter.

Weight was measured by using conventional weight machine.

Body mass index (BMI) was calculated from weight $(\mathrm{kg})$ divided by square of height in meter square. A plastic coated inch/ centimeter tape was used for the waist circumference and hip circumference measures.

Waist circumference was measured at the smallest circumference between the costal margin and the iliac crest to the nearest $0.1 \mathrm{~cm}$ while the case was standing with the abdomen relaxed, at the end of normal expiration. Where there was no natural waistline, the measurement was taken at the level of umbilicus.

Hip circumference was measured at the maximum circumference between the iliac crest and the crotch whiles the participant in standing and recorded to the nearest $0.1 \mathrm{~cm}$.

\section{Results}

In this study total 100 obese diabetes mellitus type 2 patients were included out of which 30 were males and 70 were females.

As shown in table 1 , out of 100 cases $38(38 \%)$ were in age group $>55$ years, $24(24 \%)$ in age group 50-55 years, $15(15 \%)$ in age group 40-45 years. 
Table 1: Age wise distribution of cases $(n=100)$

\begin{tabular}{|l|c|c|}
\hline Age (years) & No. of patients & $\%$ \\
\hline $25-30$ & 05 & 05 \\
\hline $30-35$ & 02 & 02 \\
\hline $35-40$ & 06 & 06 \\
\hline $40-45$ & 15 & 15 \\
\hline $45-50$ & 10 & 10 \\
\hline $50-55$ & 24 & 24 \\
\hline$>55$ & 38 & 38 \\
\hline
\end{tabular}

As shown in table 2, out of 70 cases, $61 \%$ female cases had BMI between 25-29.9\% and only 5\% female cases had BMI >or $=40.70 \%$ of male cases had BMI Between 25-29.9. In our study none of male case had $\mathrm{BMI}>$ or $=40$

Table 2: Distribution of Obese DM type 2 female cases according to BMI ( $\mathrm{n}=70)$

\begin{tabular}{|l|c|c|c|c|}
\hline BMI $\left(\mathbf{k g} / \mathbf{m}^{\mathbf{2}}\right)$ & $\begin{array}{c}\text { No. of female } \\
\text { patients }\end{array}$ & $\%$ & $\begin{array}{c}\text { No. of male } \\
\text { patients }\end{array}$ & $\%$ \\
\hline $25-29.9$ & 43 & 61 & 21 & 70 \\
\hline $30-34.9$ & 16 & 22 & 8 & 27 \\
\hline $35-39.9$ & 7 & 10 & 1 & 3 \\
\hline$\geq 40$ & 4 & 5 & 0 & 0 \\
\hline
\end{tabular}

As shown in table 3 and 4, (8)11\%, (16)22\%, and (46)67\% female patients had WHR $<0.81,0.81$ 0.85 , and $>0.85$ respectively. Among male patients, 7(23\%), 7(23\%), 7(23\%) and 9(31\%) patients had <0.9, 0.91-0.95, 0.95-1 and >1.0 WHR respectively. In female patients macrovascular complications was found in $2.8 \%, 5.7 \%$ and $25.7 \%$ respectively while in male patients $3.3 \%, 10 \%, 10 \%$ and $13.3 \%$ respectively. In female patients, micro-vascular complications was found in $1.4 \%, 7.1 \%$, and $31.4 \%$ respectively while in male micro-vascular complications was found in $3.3 \%, 6.6 \%, 13.3 \%$, and $13.3 \%$ patients respectively.

Table 3: Distribution of obese DM type 2 female cases according to WHR ( $n=70)$

\begin{tabular}{|l|c|c|c|c|}
\hline WHR & $\begin{array}{c}\text { No. of female } \\
\text { patients }\end{array}$ & $\%$ & $\begin{array}{c}\text { Macrovascular } \\
\text { Complications(\%) }\end{array}$ & $\begin{array}{c}\text { Microvascular } \\
\text { complications(\%) }\end{array}$ \\
\hline$<0.81$ & 8 & 11 & $2(2.8 \%)$ & $1(1.4 \%)$ \\
\hline $0.81-0.85$ & 16 & 22 & $4(5.7 \%)$ & $5(7.1 \%)$ \\
\hline$>0.85$ & 46 & 67 & $18(25.7 \%)$ & $22(31.4 \%)$ \\
\hline
\end{tabular}

Table 4: Distribution of obese DM type 2 male cases according to WHR ( $n=30)$

\begin{tabular}{|l|c|c|c|c|}
\hline WHR & $\begin{array}{c}\text { No. of male } \\
\text { patients }\end{array}$ & $\%$ & $\begin{array}{c}\text { Macrovascular } \\
\text { Complications(\%) }\end{array}$ & $\begin{array}{c}\text { Macrovascular } \\
\text { Complications(\%) }\end{array}$ \\
\hline$<0.90$ & 7 & 23 & $1(3.3 \%)$ & $1(3.3 \%)$ \\
\hline $0.91-0.95$ & 7 & 23 & $3(10 \%)$ & $2(6.6 \%)$ \\
\hline $0.95-1.0$ & 7 & 23 & $3(10 \%)$ & $4(13.3 \%)$ \\
\hline$>1.0$ & 9 & 31 & $4(13.3 \%)$ & $4(13.3 \%)$ \\
\hline
\end{tabular}

\section{Discussion}

In this study we studied 100 obese patients of diabetes mellitus type 2 , in which 70 were female patients and 30 were male patients. This study was conducted at department of medicine in MGM Medical College and MY Hospital Indore, MP. This study was aimed with anthropometric measurements and vascular complications in obese patients suffering from type 2 diabetes mellitus in Central India.
In our study, out of 70 cases, $61 \%$ female cases had BMI between 25-29.9\% and only 5\% female cases had BMI >or $=40.70 \%$ of male cases had BMI Between 25-29.9. In our study none of male case had $\mathrm{BMI}>\mathrm{Or}=40$. Vijay Achari et $\mathrm{al}^{1}$ observed in their study that out of 936 cases subjected to study, 596(64.2\%) were positive for the metabolic syndrome, while 516(55.6\%) tested positive for coronary artery disease, There was a strong correlations between these entities( $\mathrm{p}$ value $<0.001)$. When the individual components were 
tested for their relationship with coronary artery disease, it was found that obesity had the strongest association with the presence of ischemic heart disease.

Our study showed, (8)11\%, (16)22\%, and (46)67\% female patients had WHR <0.81, 0.810.85 , and $>0.85$ respectively. Among male patients, 7(23\%), 7(23\%), 7(23\%) and $9(31 \%)$ patients had <0.9, 0.91-0.95, 0.95-1 and >1.0 WHR respectively. In female patients macrovascular complications was found in $2.8 \%, 5.7 \%$ and $25.7 \%$ respectively while in male patients $3.3 \%, 10 \%, 10 \%$ and $13.3 \%$ respectively. In female patients, micro-vascular complications was found in $1.4 \%, 7.1 \%$, and $31.4 \%$ respectively while in male micro-vascular complications was found in $3.3 \%, 6.6 \%, 13.3 \%$, and $13.3 \%$ patients respectively. A study conducted by $\mathrm{M}$ Pascual et $\mathrm{al}^{2}$, in which they concluded that subclinical left ventricular diastolic dysfunction in present in all grades of isolated obesity, correlated with BMI, and was associated with increased systolic function in the early stages of obesity. One Indian study, R. Gupta et al $2002^{3}$, on risk factors for coronary heart disease observed that percentage of subjects who have abdominal obesity(as defined by WHR $>0.9$, and $>0.8$ in woman) as being $57.4 \%$ and $68.4 \%$ respectively. In another study (2001) it was noted that WHR was significantly higher in cases with acute myocardial infarction than controls(0.93 v.0.89).

In a study Bannerji et $\mathrm{al}^{4}$ working on cases with visceral obesity reported a men BMI of 24.5, WHR of 0.88 and waist circumference of 86.2 in Asian Indian men.

It is clear that as obesity increases in diabetes mellitus type 2 patients, it also increases the possibilities of several macro-vascular and microvascular complications. So early management of obesity in diabetes mellitus type 2 patients by regular exercise, change in dietary pattern, and somehow by medical management can help more before development of deadly vascular complications.

\section{Conclusions}

Basic anthropometrics measurements (BMI+WHR) are simple clinical parameters to evaluate obese DM type 2 cases for CVS complications. Obese DM type 2 cases with abnormal WHR and BMI may have abnormalities in ECG \& 2D ECHO DOPPLER. Hence ECG \& 2D ECHO DOPPLER study may help for proper evaluation of obese DM type 2 cases.

\section{Disclosures}

Funding: None

Conflict of interests: Not declared

Ethical Approval: Study was approved by institutional ethical board.

\section{References}

1. Vijay Achari, AK Thakur, Arun k Sinha. The Metabolic Syndrome- Its Prevalence and Association with Coronary Artery Disease in Type 2 Diabetes. JIACM 2006; 7(1): 32-8.

2. M Pascual, D A Pascual, F Soria et al. Effects of isolated obesity on systolic and diastolic left ventricular function. The Heart 2003; 89: 1152-1156.

3. Gupta R, Gupta VP, Sarna M et al. Prevalence of coronary heart disease and risk factors in an urban Indian population: Jaipur Heart Watch-2. Indian Heart Journal. 2002; 54: 56-66.

4. Banerji M, Faridi N, Atluri R, Chaiken RL, Lebovitz HE. Body composition, visceral fat, leptin and insulin resistance in Asian Indian Men. J Clin Endocrinol Metab 1999; 84: 137-44. 